\title{
Erratum to: The Hamiltonian dynamics of Hořava gravity
}

\author{
Deniz O. Devecioğlu ${ }^{1, a}$, Mu-In Park ${ }^{2, b}$
}

${ }^{1}$ School of Physics, Huazhong University of Science and Technology, Wuhan 430074, Hubei, China

${ }^{2}$ Center for Quantum Spacetime, Sogang University, Seoul 121-742, Republic of Korea

Received: 30 July 2020 / Accepted: 2 August 2020 / Published online: 20 August 2020

(C) The Author(s) 2020

Erratum to: Eur. Phys. J. C

https://doi.org/10.1140/epjc/s10052-020-8139-8

This erratum corrects some typos in the article.

In Ref.[1], Eq. (A17) should be corrected as follows:

$\dot{\sqrt{g}}=\left(\frac{\kappa^{2}}{2}\right) \frac{N \pi}{1-D \lambda}+2 \nabla_{i} N^{i}$.

In Eq. (42), $C^{i}$ should be read as $\widetilde{C}^{i}$.

Open Access This article is distributed under the terms of the Creative Commons Attribution 4.0 International License (http://creativecomm ons.org/licenses/by/4.0/), which permits unrestricted use, distribution, and reproduction in any medium, provided you give appropriate credit to the original author(s) and the source, provide a link to the Creative Commons license, and indicate if changes were made.

Funded by SCOAP ${ }^{3}$.

\section{Reference}

1. D.O. Devecioglu, M.I. Park, Eur. Phys. J. C 80, 597 (2020). arXiv:2001.02556 [hep-th]

The original article can be found online at https://doi.org/10.1140/

epjc/s10052-020-8139-8.

a e-mail: dodeve@gmail.com

b e-mail: muinpark@gmail.com (corresponding author) 